\title{
Incidencia de la reforma laboral en el empleo público
}

\section{Incidence of the labor reform in public employment}

\author{
Francisco Ramos Moragues \\ Profesor Contratado Doctor en Derecho del Trabajo y de la Seguridad Social \\ Universitat de València \\ ORCID ID: 0000-0002-4230-0699
}

doi: https://doi.org/10.20318/labos.2022.6645
Resumen: La nueva reforma del mercado de trabajo, aprobada mediante el Real Decreto Ley 32/2021, de 28 de diciembre, despliega sus efectos, fundamentalmente, en el ámbito privado de las relaciones laborales. No obstante, existen algunas pre- visiones que afectan directa o indirectamente a las Administraciones Públicas, en su condición de empleadores, y al personal laboral que presta servicios en ellas. El objeto de este trabajo es dar cuenta de los cambios introducidos por la reforma laboral en el empleo público.

Palabras clave: Administración Pública; reforma legislativa; relación laboral; empleo público.

Abstract: $\quad$ The new reform of the labor market, approved by Royal Decree Law 32/2021, of December 28, produce its effects, fundamentally, in the private sphere of labor relations. However, there are some provisions that directly or indirectly affect the Public Administrations, in their capacity as employers, and the workforce that provides services in them. The purpose of this paper is to explain the changes introduced by the labor reform in public employment.

Keywords: $\quad$ Public Administration; law reform; labor relation; public employment.

\section{A modo de introducción}

Con fecha 30 de diciembre de 2021, se ha publicado en el Boletín Oficial del Estado, el Real Decreto-ley 32/2021, de 28 de diciembre, de medidas urgentes para la reforma laboral, la garantía de la estabilidad en el empleo y la transformación del mercado de trabajo (en lo sucesivo, RDL 32/2021). Según reza su Disposición final 8a , la norma entra en vigor al día siguiente de su publicación; excepto para determinadas materias cuya aplicación efectiva se difiere a los tres meses desde su aprobación.

La mayor parte de las modificaciones que introduce esta reforma se circunscriben al ámbito privado de las relaciones laborales, esto es, tienen como destinatarios a los trabajadores y empresarios del sector privado. Sin embargo, el legislador también incorpora en el RDL 32/2021 algunas

*francisco.ramos@uv.es 
previsiones, particularmente, a través de sus disposiciones adicionales, transitorias y derogatoria, que tienen incidencia, directa o indirecta, sobre el empleo público laboral. El impacto de los cambios que se introducen en este ámbito es desigual dependiendo del caso concreto; o, incluso, de la interpretación que se realice del alcance de los mismos, pues no siempre va a ser una tarea sencilla descifrar las intenciones del legislador.

El objeto de estudio del presente trabajo se dirige, precisamente, a dar cuenta de los cambios introducidos por la reforma laboral con repercusión en el sector público. Para situar el análisis en sus justos términos, es imprescindible abordar esta tarea trayendo a colación dos normas esenciales en este terreno. Me refiero, de un lado, al Real Decreto Legislativo 5/2015, de 30 de octubre, por el que se aprueba el texto refundido de la Ley del Estatuto Básico del Empleado Público -en lo sucesivo, EBEP-; y, de otro lado, a la Ley 20/2021, de 28 de diciembre, de medidas urgentes para la reducción de la temporalidad en el empleo público. La primera de las disposiciones citadas constituye, qué duda cabe, la norma de cabecera por lo que se refiere al régimen jurídico del personal que presta servicios en las Administraciones Públicas. La segunda, en cambio, tiene un ámbito objetivo mucho más limitado. Por cuanto aquí interesa, establece diversas medidas para controlar la contratación temporal, entre las que sobresalen la configuración de un régimen de responsabilidad institucional y personal, así como el reconocimiento de una compensación económica en favor de aquellos empleados que han sufrido un perjuicio derivado del uso abusivo de la temporalidad.

\section{El recurso a la contratación laboral en el sector público: Disposición Adicional $4^{a}$, aparta- dos primero y segundo del RDL 32/2021}

La primera de las disposiciones del RDL 32/2021 que inciden en el empleo público es la adicional cuarta (DA 4a), rubricada "Régimen aplicable al personal laboral del sector público". De entrada, una simple lectura de la norma pone de manifiesto que el título de la disposición no se corresponde con su contenido. Ninguno de los tres párrafos que la conforman -a lo sumo, con gran generosidad, el tercero de ellos- aluden a la norma aplicable a este colectivo de servidores públicos, sino a una de las modalidades contractuales que pueden utilizarse por las entidades públicas y a las limitaciones, económicas y de acceso, que existen para su celebración y que traen causa, como suele ocurrir en este terreno, en la naturaleza pública del empleador.

Dejando al margen la previsión referida al contrato de sustitución en caso de vacante, que por su entidad será objeto de tratamiento específico en el siguiente epígrafe, el primero de los apartados se refiere a la posibilidad de que las Administraciones Públicas celebren "contratos por tiempo indefinido e indefinido fijo-discontinuo" 1 y lo condiciona a que éstos "resulten esenciales para el cumplimiento de los fines" que las administraciones públicas y las entidades que conforman el sector público institucional tenga encomendados, previa expresa acreditación. A dicha previsión, hay que ańadir -segundo apartado- una limitación desde el punto de vista económico, según la cual, caso de existir una tasa de reposición específica, deberá respetarse.

Son varias las consideraciones que cabe efectuar en relación con los dos primeros apartados que se acaban de exponer. De entrada, respecto al ámbito subjetivo, la previsión se dirige no sólo a las administraciones públicas strictu sensu, es decir, las de base territorial, sino que se extiende su aplicación al "sector público institucional", que incluye dos grandes categorías: los organismos públicos y enti-

\footnotetext{
${ }^{1}$ Habida cuenta de la confusión terminológica que caracteriza al empleo púbico laboral, donde se entrelazan conceptos como el de trabajadores fijos, indefinidos, indefinidos no fijos, etc. No parece muy conveniente añadir uno más "indefinido fijo-discontinuo"; sobre todo porque tal diferenciación no supone ningún valor añadido.
} 
dades de derecho público vinculados o dependientes de las Administraciones Públicas y las entidades de derecho privado vinculadas o dependientes de las Administraciones Públicas ${ }^{2}$.

Entrando ya en el análisis del contenido, la alusión a que una entidad pública puede recurrir a la contratación laboral indefinida es, a mi juicio, una afirmación redundante e incompleta. Es redundante en la medida en que se trata de una posibilidad que ya se reconoce expresamente por la normativa actualmente vigente -art. 11.1 EBEP- y se confirma, además, a la vista de los datos estadísticos oficiales ${ }^{3}$.

Por su parte, el calificativo de "incompleta" obedece a que una interpretación literal de la norma podría llevar al intérprete a entender que sólo cuando se trate de contratos indefinidos -sea en su vertiente ordinaria o como fijos discontinuos- se requiere que la celebración del contrato sea esencial para el cumplimiento de los fines de la entidad pública. No sería correcta esta interpretación, pues, independientemente de la modalidad contractual laboral de que se trate -vaya por delante que todas son admisibles, incluyendo las de duración determinada- la incorporación de personal, en la medida en que se trata de acceder a la función pública, siempre ha de considerarse "esencial" para que el organismo público en cuestión pueda cumplir con los fines y objetivos que tiene encomendados. Partiendo de esta idea, es el propio ente público quien ha de valorar y acreditar sus necesidades de personal y, en su caso, proceder a la oferta de empleo público, así como a la convocatoria y cobertura de las plazas ofertadas a través de un procedimiento selectivo que cumpla los requisitos legales, en especial, los principios rectores del acceso al empleo público.

Por supuesto, tan importante -o más- que el requisito de que la decisión de contratar empleados públicos resulte esencial a los fines que persigue la entidad pública, es que tenga encaje presupuestario. Es aquí donde entra en juego la denominada tasa de reposición, que, como es bien sabido, consiste en un indicador que se utiliza para determinar el porcentaje de vacantes que pueden cubrirse con la incorporación de personal. Pues bien, la disposición adicional cuarta del RDL 32/2021 aclara que, amén de respetar la tasa de reposición "ordinaria”, esto es, la que se refleja cada ejercicio en la correspondiente Ley de presupuestos generales del Estado ${ }^{4}$, si se precisara una tasa de reposición específica para cubrir tales las plazas, la cobertura de las mismas se sujetará a la obtención de la preceptiva autorización del Ministerio de Hacienda y Función Pública. Esta exigencia no merece mayor comentario y se justifica en la necesaria política de contención del déficit público.

En suma, ahora como antes, la decisión de contratar personal laboral sigue correspondiendo a las entidades públicas, que podrán utilizar cualquier modalidad contractual prevista en el Estatuto de los Trabajadores. Ni que decir tiene que, si se trata de un contrato temporal, deberá estar presente la causa que legitime la temporalidad. Por lo demás, la decisión de contratar está condicionada por la observancia de una serie de exigencias impuestas por el legislador ordinario. Me refiero, en particular, a la dotación presupuestaria de los puestos que se van a cubrir; a la obligación de confeccionar la pertinente Relación de Puestos de Trabajo —o instrumento de ordenación similar-; y, por último, a la necesidad de que el puesto de trabajo esté reflejado en la correspondiente Oferta de Empleo Público.

\footnotetext{
${ }^{2}$ Un análisis de la tipología de administraciones públicas y sus principales características en RAMOS MORAGUES, Francisco, "Delimitación del sector público y ámbito aplicativo del EBEP”, en AA.VV. (Dir. BLASCO PELLICER, Ángel y LÓPEZ BALAGUER, Mercedes), Las relaciones laborales en el sector público, Valencia, Ed. Tirant lo Blanch, 2019, págs. 13 a 54.

${ }^{3}$ En efecto, es un hecho incontrovertido el que las Administraciones Públicas, de antiguo, vienen confeccionando sus plantillas mediante la contratación de trabajadores de conformidad con la legislación laboral. Vid., Boletín Estadístico del Personal al Servicio de las Administraciones Públicas (enero 2021). Disponible en: http://www.mptfp.es/dam/es/portal/funcionpublica/funcion-publica/rcp/boletin/Boletines/200701_Boletin_julio_2021.pdf.pdf

${ }^{4}$ Esta parte obedece a una modificación a la DA 4a del RDL 32/2021, por parte del Real Decreto-ley 1/2022, de 18 de enero, el cual, como curiosidad, en ninguna parte de su extenso título alude a que modifica, tras unas pocas semanas de vida, la reforma laboral.
} 
Como colofón, quisiera significar a modo de recordatorio, que la Administración Pública goza de una amplia libertad para decidir si las necesidades de personal se cubren mediante empleados públicos laborales o a través personal funcionarial. No se trata, eso sí, de una facultad omnímoda, sino que aparece condicionada por la reserva de funciones contenida en el art. 9.2 EBEP, según la cual, el ejercicio de las funciones que impliquen la participación directa o indirecta en el ejercicio de las potestades públicas o en la salvaguardia de los intereses generales del Estado y de las Administraciones Públicas corresponden exclusivamente a los funcionarios públicos.

\section{Singularidades del nuevo contrato de sustitución por vacante en las Administraciones Pú- blicas: régimen de responsabilidades y compensación económica}

El art. 15.3 in fine ET, en la redacción dada por el RDL 32/2021 (vigente a partir del 31 de marzo de 2022), contempla la posibilidad de que se celebre el contrato de sustitución para la cobertura temporal de un puesto de trabajo mientras se desarrolla el proceso de selección o promoción para su cobertura definitiva a través de un contrato fijo. La norma, además, fija dos límites: 1) Su duración no podrá ser superior a 3 meses o al plazo previsto en el convenio colectivo; 2) Se prohíbe que pueda suscribirse nuevamente el contrato con el mismo objeto si se ha superado la duración máxima.

Partiendo de la norma común, la ya aludida Disposición adicional 4a del RDL 32/2021, en su párrafo tercero, reconoce a las Administraciones Públicas la opción de celebrar estos contratos, manteniendo el mismo objeto, pero con una importante singularidad en punto a su duración máxima. En este ámbito, no existe la limitación legal de los tres meses, sino que se permite que su duración se prolongue hasta que finalice el proceso de selección por el que se cubre el puesto definitivamente. Se trata de una previsión que, en todo caso, no puede considerarse innovadora, pues ya el RD 2720/1998 daba cobertura normativa a una modalidad de "interinidad por vacante" en el ámbito de las Administraciones Públicas; y lo hacía en términos prácticamente coincidentes con la regulación vigente. Ahora, eso sí, se recoge en una norma con rango de ley. Dicho esto, vaya por delante que el incremento que se hace de la duración máxima del contrato es perfectamente razonable y obedece a la mayor complejidad que conlleva la puesta en marcha, desarrollo y resolución de los procesos selectivos en el sector público, que han de sujetarse a los imperativos legales y constitucionales habidos en la materia, lo que se traduce en una ampliación considerable de los tiempos de espera desde que se convoca la plaza hasta que la misma se cubre definitivamente.

La Disposición adicional $4^{\text {a }}$ completa su regulación señalando, de una parte, que la cobertura del proceso selectivo ha de llevarse a cabo respetando los principios de igualdad, mérito y capacidad; y, de otra, remitiéndose a lo dispuesto en la Ley 20/2021, de 28 de diciembre, de medidas urgentes para la reducción de la temporalidad en el empleo público. Con respecto a la primera parte, se trata de una reiteración de los principios que han de presidir el acceso al empleo público, tal y como ya se viene exigiendo, a nivel constitucional, por los arts. 23.2 y $103 \mathrm{CE}$; y, a nivel de legalidad ordinaria, por art. 55 y, más recientemente, por el art. 11.3 -en relación con el personal temporal laboralambos preceptos, del EBEP.

Más interesante, sin duda, es la remisión a la Ley 20/2021. Fundamentalmente, porque dicha Ley ha incorporado, a través de la nueva Disposición Adicional $17^{\mathrm{a}}$ al EBEP, un régimen de responsabilidades, tanto a nivel institucional como personal, para el caso en el que se incumplan los plazos máximos de permanencia como personal temporal; y, al mismo tiempo, porque prevé una "compensación económica" en favor del personal temporal que se vea afectado por tal circunstancia. 
Categoría esta, la de "personal temporal", en la que no sólo se incluye a los funcionarios interinos sino también a los empleados públicos laborales 5 . Vayamos por orden.

Comenzando por el régimen de responsabilidades, destacan dos previsiones: de un lado, con un alcance más general, se responsabiliza a las Administraciones Públicas del cumplimiento de las previsiones contenidas en la Ley 20/2021 y, en especial, de velar por evitar cualquier tipo de irregularidad en la contratación laboral temporal y los nombramientos de personal funcionario interino.

De otro lado, se produce una remisión a la normativa vigente en cada una de las Administraciones Públicas a efectos de dirimir la responsabilidad que pueda derivarse para el empleado público que lleve a cabo "actuaciones irregulares". Interesa traer a colación ahora, por su condición de norma básica, el art. 94 EBEP, según el cual, no sólo se impone a las Administraciones Públicas el deber de corregir (literalmente, se dice "corregirán") disciplinariamente las infracciones del personal a su servicio de acuerdo con los clásicos principios de legalidad, tipicidad, irretroactividad, proporcionalidad, culpabilidad y presunción de inocencia; sino que se admite expresamente la posibilidad de que junto a la imposición de sanciones disciplinarias, se pudieran derivar, en atención a la entidad de las infracciones cometidas, otro tipo de responsabilidad patrimonial o, incluso, penal.

A la espera de ver cómo se concreta esta cuestión en la normativa específica disciplinaria de cada Administración Pública, lo que si aclara la disposición adicional $17^{\text {a }}$ del EBEP es que se considerará como nulo de pleno derecho "todo acto, pacto, acuerdo o disposición reglamentaria, así como las medidas que se adopten en su cumplimiento o desarrollo, cuyo contenido directa o indirectamente suponga el incumplimiento por parte de la Administración de los plazos máximos de permanencia como personal temporal".

Manteniendo esa cautela sobre cómo se desarrollará y, todavía más importante, sobre si tendrá una aplicación efectiva, su mera inclusión y los términos en que se hace es un aspecto a valorar positivamente. Que en la Administración Pública se hace un uso inadecuado de la temporalidad es un hecho que no admite discusión, y así viene siendo denunciado desde tiempo atrás por la doctrina científica ${ }^{6}$ amén de por otras instituciones públicas ${ }^{7}$. Pero igual de indiscutible es que para corregir esta situación disfuncional resulta capital arbitrar mecanismos efectivos que permitan exigir responsabilidades a las autoridades o empleados públicos que prolongan de manera artificial la relación de servicios o laboral del empleado interino o temporal ${ }^{8}$. El paso del tiempo será lo que nos permita verificar si finalmente se trata de una previsión meramente programática, como otras similares que

${ }^{5}$ Debe advertirse que, en aplicación de lo dispuesto por la Disposición transitoria segunda de la Ley 20/2021, las previsiones contenidas en su artículo 1 -donde se ubican las medidas de control de la temporalidad- serán de aplicación respecto del personal temporal nombrado o contratado con posterioridad a su entrada en vigor.

${ }^{6}$ Hace más de dos décadas, MERCADER, en una obra que constituye un referente en esta materia, ya se refería de críticamente a la utilización flexible que hacía la Administración de las distintas modalidades de contratación temporal previstas en el ET, lo que había conducido, con el visto bueno de la jurisprudencia unificada del Tribunal Supremo, hacia una progresiva desnaturalización de las causas que legitiman el recurso a la contratación temporal en el ámbito público. MERCADER UGUINA, Jesús Rafael, $L a$ contratación temporal en la jurisprudencia del Tribunal Supremo, Valencia, Ed. Tirant lo Blanch, 1999, pág. 22.

El informe realizado por el Defensor del Pueblo denominado Funcionarios interinos y personal eventual: la provisionalidady temporalidad en el empleo público (2003) ya entonces daba buena cuenta de este problema. El texto íntegro del documento se encuentra disponible en: https://www.defensordelpueblo.es/informe-monografico/funcionarios-interinos-y-personal-eventual-la-provisionalidad-y-temporalidad-en-el-empleo-publico-2003/

${ }^{8}$ Así lo evidenciaba en su Informe, la Comisión de expertos que se creó para la elaboración de los trabajos preparatorios del Estatuto Básico del Empleado Público. En dicho documento ya se defendía, con gran cierto, a mi entender, la conveniencia de que en el texto de la ley se incluyera, expresamente, el deber de emitir un informe previo por el titular del órgano que tuviera a su cargo el asesoramiento legal de la Administración, organismo o departamento en que presta sus servicios el trabajador, sobre la irregularidad de la prórroga expresa o implícita del contrato; de modo que, tras la emisión del referido informe, sería el titular del órgano de contratación quien asumiría la responsabilidad que le pudiera corresponder por la irregularidad cometida, ya fuera esta de carácter disciplinario, patrimonial o, en su caso, penal. Vid., Informe de la Comisión de expertos para el estudio y preparación del Estatuto Básico del Empleado Público, Madrid, Ed. Instituto Nacional de Administración Pública, 2005, págs. 62-63. 
ya ha habido en este sentido; o si, por el contrario, ha servido de base para edificar un verdadero y eficaz régimen de responsabilidades.

Retomando el análisis, el régimen de responsabilidades al que se ha aludido tiene como detonante el incumplimiento de los "plazos máximos de permanencia como personal temporal". Ello exige cuestionarnos sobre qué plazos son estos. Pues bien, en coherencia con las modificaciones que introduce la Ley 20/2021 en la redacción del art. 10 EBEP, a través de las cuales, se endurecen las previsiones legales relativas a la duración máxima del nombramiento del interino por vacante; hemos de considerar, al menos en relación con el contrato que estamos analizando, que tanto la batería de responsabilidades como la compensación económica que veremos a continuación se activa con el transcurso del plazo de 3 años a contar desde la celebración del contrato.

Aclarado este extremo, es el momento de referirnos a cuál es la "compensación económica" que contempla el legislador y qué reglas se siguen para su determinación. Centrándonos, por razones obvias, en el caso del personal laboral temporal, la Disposición adicional $17^{a}$ del EBEP señala que estos trabajadores, en caso de que se incumpla el plazo máximo de permanencia -en el supuesto de la interinidad por vacante: 3 años- tienen derecho a una compensación económica equivalente a veinte días de sus retribuciones fijas por ańo de servicio, prorrateándose por meses los períodos inferiores a un ańo, con un tope máximo de 12 mensualidades. Además, se indica que el derecho a la compensación seńalada se produce "sin perjuicio de la indemnización que pudiera corresponder por vulneración de la normativa laboral específica”.

Para cohonestar ambas previsiones -indemnización laboral y compensación económica - la propia disposición adicional establece una regla para determinar esta última. Literalmente, se afirma que: "Dicha compensación consistirá, en su caso, en la diferencia entre el máximo de veinte días de su salario fijo por año de servicio, con un máximo de doce mensualidades, y la indemnización que le correspondiera percibir por la extinción de su contrato, prorrateándose por meses los períodos de tiempo inferiores a un ańo [...]".

Como ha destacado la doctrina más autorizada', a través de esta fórmula se configura por el legislador un régimen "enrevesado", que, además, convierte en "inoperante" esta compensación económica a la luz de la reciente jurisprudencia de la Sala Cuarta del Tribunal Supremo en punto a las consecuencias que derivan de ocupar una plaza de personal interino por vacante durante un período inusual e injustificadamente largo. En efecto, a raíz de la interpretación defendida en la conocida sentencia del Tribunal de Justicia de la Unión Europea, de 3 de junio de 2021 (Caso IMDRA) ${ }^{10}$, el Tribunal Supremo, mediante su sentencia de 28 de junio de $2021^{11}$, dictada por el Pleno de la Sala ha precisado y, en algún punto, rectificado, la doctrina que hasta ese momento venía aplicando en relación con la duración máxima de la interinidad por vacante y sobre cuándo ésta debía considerarse fraudulenta. A los exclusivos efectos que ahora nos interesan, el cambio doctrinal puede sintetizarse en que la superación de un plazo de 3 años -a contar desde la celebración del contrato de interinidad- sin que la Administración correspondiente haya procedido a la cobertura de definitiva de la plaza, hace pensar que, con carácter general, estamos ante una duración excesiva e injustificadamente larga. En estos casos, la consecuencia que se deriva es que ese trabajador debe considerarse como "personal indefinido no fijo".

${ }^{9}$ Vid. SEMPERE NAVARRO, Antonio Vicente, 2021, "La temporalidad en el sector público tras la Ley 20/2021 de 28 diciembre", en Elderecho.com. [en línea]. Disponible en: https://elderecho.com/la-temporalidad-en-el-sector-publico-tras-la-ley-20-2021-de8-diciembre [Consulta: 34-01-2022].

${ }^{10}$ asunto C-726/2019, Imdra.

${ }^{11} R^{o}$. 3263/2019. Esta tesis jurisprudencial ha sido reiterada con posterioridad. Entre las más recientes: STS de 2 de diciembre de 2021 (Ro. 4609/2018). 
Esta figura, polémica donde las haya, como muestra la enorme litigiosidad generada en torno a ella y su extensísimo tratamiento doctrinal, implica, a grandes rasgos, que el empleado público sigue ocupando el puesto como "personal indefinido (pero no fijo)" hasta que se proceda a la cobertura definitiva de la plaza a través del correspondiente procedimiento selectivo acorde con los principios de igualdad, mérito y capacidad. Será entonces cuando se producirá la extinción del contrato de trabajo. Ahora bien, la situación del indefinido no fijo, por lo que a su régimen extintivo se refiere, puede ofrecer diversos escenarios: a) Que la Administración proceda a la amortización de la plaza. En ese caso, el cauce extintivo adecuado es el art. 51 y/o 52 ET, con derecho a una indemnización de veinte días de salario por año de servicio y un tope de 12 mensualidades; b) Que se lleve a cabo la cobertura reglamentaria de la plaza, y la obtuviera un tercero. La tesis jurisprudencial vigente, tras no pocos vaivenes, es que el trabajador tendrá derecho a la misma indemnización que la señalada en la opción a), esto es, la propia del despido objetivo; c) Que se produzca la cobertura reglamentaria de la plaza por el propio «indefinido no fijo». En este supuesto, dado que se ha producido la transformación del vínculo con consolidación de empleo por parte del trabajador, en principio cabe entender que aquél no tendría derecho a indemnización alguna; d) Que se produzca el despido disciplinario u objetivo del trabajador. Aquí, la existencia de indemnización o no y su concreto importe, se rige por lo dispuesto en la legislación laboral y dependerá, como es sabido, de si el mismo se califica de procedente o improcedente. Las posibilidades son: que no haya indemnización alguna, que ésta sea de veinte días o que se eleve a 33 días, en caso de improcedencia.

Volvamos a la regla prevista en la nueva Disposición adicional 17a EBEP: "Dicha compensación consistirá, en su caso, en la diferencia entre el máximo de veinte días de su salario fijo por año de servicio, con un máximo de doce mensualidades, y la indemnización que le correspondiera percibir por la extinción de su contrato, prorrateándose por meses los períodos de tiempo inferiores a un año [...]". Pues bien, la inmensa mayoría de los escenarios expuestos en el párrafo anterior no permiten el juego de la nueva "compensación económica". En todos ellos, la indemnización que prevé la norma laboral es superior (33 días) o como poco igual (20 días) a la prevista en el EBEP. De ahí que resulte muy adecuada, a mi parecer, la valoración de "inoperante" que ha señalado algún autor; lo que le lleva a vincular la existencia de esta regla a una razón distinta, a saber, minorar la litigiosidad al atribuir ex lege, esto es, sin necesidad, de acudir a los tribunales, la misma compensación patrimonial ${ }^{12}$. Quizás el único escenario posible por carecer de indemnización, sería el de cobertura reglamentaria de la plaza por el propio indefinido no fijo. Sin embargo, es una hipótesis fácilmente descartable si tenemos en cuenta que, por ejemplo, en los nuevos procesos de estabilización del empleo temporal, la compensación económica sólo se prevé para quien, participando, no logra superarlo; no para quien finalmente obtiene la plaza.

Para zanjar este tema, tan sólo apuntar a un par de aspectos formales sobre la aludida "compensación económica”: en primer lugar, es necesario que se produzca la extinción contractual, de ahí que se afirme que "el derecho a esta compensación nacerá a partir de la fecha del cese efectivo"; de otro lado, la cuantía estará referida exclusivamente al contrato del que traiga causa el incumplimiento, lo cual, como ya se ha avanzado, supone desatender la doctrina jurisprudencial consolidada en punto a la unidad esencial del vínculo para los casos de sucesión de contratos temporales ${ }^{13}$.

${ }^{12}$ SEMPERE NAVARRO, Antonio Vicente, 2021, "La temporalidad en el sector público tras la Ley 20/2021 de 28 diciembre", en Elderecho.com. [en línea]. Disponible en: https://elderecho.com/la-temporalidad-en-el-sector-publico-tras-la-ley-20-2021-de8-diciembre [Consulta: 34-01-2022].

${ }^{13}$ SEMPERE NAVARRO, Antonio Vicente, 2021, "La temporalidad en el sector público tras la Ley 20/2021 de 28 diciembre", en Elderecho.com. [en línea]. Disponible en: https:/elderecho.com/la-temporalidad-en-el-sector-publico-tras-la-ley-20-2021-de8-diciembre [Consulta: 24-01-2022]. 


\section{La contratación de duración determinada como vía para la ejecución de proyectos o progra- mas temporales específicos}

Otra de las previsiones que se contienen en la reforma laboral y que tiene incidencia en el sector público, es la Disposición adicional 5a del RDL 32/2021. La norma proclama de forma expresa la posibilidad de que las entidades que integran el sector público suscriban contratos de duración determinada en dos supuestos que se corresponden con los dos primeros párrafos que conforman la citada disposición: a) de un lado, cuando se trate de contratos vinculados a la ejecución de proyectos en el marco del Plan de Recuperación, Transformación y Resiliencia -párrafo primero-; b) de otro lado, cuando se trate de contratos necesarios para ejecutar programas de carácter temporal que se financien por la Unión Europea -párrafo segundo-. En ambos casos, la duración de los contratos se vincula a la del programa o proyecto; mientras que la selección de los candidatos, obvio es decirlo, ha de efectuarse a través de procesos selectivos que preserven los mentados requisitos de igualdad, mérito y capacidad.

A mi juicio, la razón por la que el legislador ha querido reconocer en la mencionada disposición adicional esta posibilidad, hay que relacionarla directamente con la desaparición del contrato de obra o servicio. La aludida modalidad contractual se ajustaba a la perfección para atender este tipo de necesidades temporales. Tal vez por ello, con el fin de evitar cualquier duda en torno a si las entidades públicas podían seguir recurriendo a la contratación laboral temporal con el nuevo marco contractual diseńado por la reforma laboral, el legislador ha optado por su reconocimiento expreso.

El problema es que la incertidumbre se traslada ahora a qué contrato temporal han de emplear los organismos públicos para atender estas necesidades. Lo cierto es que la solución no es sencilla. En principio, cabrían dos alternativas:

a) la primera ellas, sería recurrir a los nuevos contratos de sustitución o de circunstancias de la producción (art. $15 \mathrm{ET}$ ). Sin embargo, esta solución presenta serios inconvenientes, cuando no impedimentos absolutos. En el caso del contrato por sustitución, no estaríamos ante una de las causas que la norma estatutaria establece como habilitantes para celebrar el contrato: ni hay un trabajador con reserva del puesto al que sustituir; ni tampoco una vacante temporal que deba proveerse definitivamente. En el supuesto del contrato por circunstancias de la producción, para el caso - no exento de dificultad- de que pudiera entenderse que tiene cabida en su objeto, se plantearía un problema de orden funcional, pero no menor, pues la duración ordinaria de este contrato es, como máximo, de seis meses. Lapso temporal que no se corresponde con la duración que, habitualmente, tienen este tipo de proyectos o programas, que, por lo general, suele ser superior.

b) La segunda alternativa es que la atención de estas necesidades temporales se lleve a cabo a través de contratos temporales ad hoc. En pocas palabras, se trataría de regular una suerte de "contrato de obra o servicio específico", aunque la denominación fuera distinta, que se ajustase a este tipo proyectos o programas.

Habrá que esperar, en fin, a un futuro desarrollo normativo para ver cuál es la solución que propone el legislador.

Un problema de orden similar, aunque con matices propios, lo encontramos en otro supuesto específico, a saber, el de contratación de investigadores por las Administraciones Públicas y sus organismos públicos vinculados o dependientes. De manera más concreta, se trataría de los contratos de obra o servicio asociados a un proyecto específico de investigación o de inversión. Pues bien, para estos supuestos, lo único que establece el RDL 32/2021 -Disposición transitoria tercera, párrafo segundo- es una singularidad en torno al régimen transitorio aplicable para los contratos que se 
encuentren vigentes a 31 de diciembre de 2021. Literalmente, se afirma que: "los contratos por obra o servicio determinados [...] vinculados a un proyecto específico de investigación o de inversión de duración superior a tres años y que estén vigentes [...] mantendrán su vigencia hasta el cumplimiento de la duración fijada de acuerdo a su normativa de aplicación, con el límite máximo de tres ańos contados a partir de la citada fecha”.

La similitud con los supuestos recogidos en la Disposición adicional quinta RDL 32/2021, la encontramos en que la relación laboral en estos casos se venía formalizando, igualmente, a través del contrato de obra o servicio determinado. Sin embargo, en estos casos, de ahí lo de perfil propio, nada se dice, pese a la desaparición del anterior art. 15.1 letra a) ET, sobre la posibilidad de seguir realizando contratos de duración determinada y, mucho menos, se da alguna idea sobre cuál ha de ser la formula contractual adecuada para instrumentar este tipo de relaciones laborales. Ni que decir tiene que, aclarada la situación respecto a los contratos vigentes -regla transitoria expuesta-, el problema se presenta en el futuro inmediato. De nuevo, se abren varias opciones y ninguna está exenta de problemas:

a) Si la necesidad de contratación surge en el intervalo temporal que va desde el 31 de diciembre de 2021 hasta el 30 de marzo de 2022, la entidad pública va a poder seguir celebrando un contrato de obra o servicio, pero - primer inconveniente- su duración no podrá exceder de los seis meses (Disposición transitoria cuarta RDL 32/2021). Y digo inconveniente porque los proyectos de investigación y de inversión suelen tener una duración que supera los seis meses. ¿Qué ocurrirá entonces?: si el trabajador continúa prestando servicios -que será, por otro lado, lo habitual, ya que el proyecto seguirá vigente- esa relación se convertirá en indefinida. ¿Hasta cuándo? Hasta que finalice la obra o servicio, momento en el cual, habría que proceder al despido objetivo ex art. 52 letra e) ET, con derecho a la indemnización establecida al efecto.

b) Si la necesidad de contratación surge a partir del 31 de marzo de 2022, y a falta de una previsión expresa que siga admitiendo el recurso a la contratación de duración determinada, las posibilidades se reducen a celebrar un contrato indefinido que se mantendrá hasta que finalice el proyecto, debiendo producirse entonces el despido objetivo en los mismos términos que en el supuesto anterior.

La solución, a mi juicio, sería, de nuevo, la de reintroducir el contrato de obra o servicio para este tipo de supuestos específicos; o bien un contrato ad hoc con distinta denominación, pero de características similares, que se ajustase a este tipo de necesidades temporales. A la espera de ver cómo afronta el problema el legislador, si quisiera señalar que, si finalmente se llega a la conclusión de que en estos casos sólo es posible realizar contratos indefinidos, ello provoca un efecto perverso, consistente en reducir artificialmente la tasa de temporalidad a costa de un personal indefinido que, al final, se vería abocado a un despido, y que, a mayor abundamiento, correspondería su sostenimiento al erario público.

\section{Efectos de la contratación temporal irregular o abusiva: ¿̨ha desaparecido el personal inde- finido no fijo?}

No es dudoso que esta reforma laboral se marca como uno de sus objetivos prioritarios, poner freno al uso claramente abusivo que desde tiempo atrás, se ha venido haciendo de la contratación laboral temporal en nuestro país. A tal fin, se configura por el legislador un nuevo marco de contratación 
laboral en el que se dé preponderancia a la contratación indefinida. Para ello, entre otras medidas, se reformulan algunos contratos indefinidos ya existentes, se redefinen las causas de temporalidad, se prevén nuevas sanciones en caso de incumplimiento de la normativa en materia de temporalidad o se incrementa la cotización a la seguridad social para los contratos de duración determinada de escasa duración.

Una de las medidas que se dirigen a ese fin último de acabar con la temporalidad irregular se contiene en el art. 15.4 ET; precepto en el que se afirma que "las personas contratadas incumpliendo lo establecido en este artículo adquirirán la condición de fijas”. Una previsión de corte similar se contenía en la versión anterior a la reforma del art. 15.3 ET, que presumía el carácter indefinido del contrato de trabajo cuando se hubiera celebrado en fraude de ley. El hecho de que el legislador afirme ahora que las personas trabajadoras adquirirán la condición de "fijas", podría suscitar la duda, como han apuntado algunos de los primeros comentaristas de la norma ${ }^{14}$, sobre si ello supone el fin de la figura del indefinido no fijo. Planteamiento que podría verse reforzado por la derogación de la Disposición adicional 15a del ET, especialmente, de su apartado segundo, donde se recogía, implícitamente, aquella figura.

De llegar a esta conclusión, el cambio sería trascendental por sus indudables consecuencias prácticas. Y es que, ello supondría que en supuestos de contratación temporal fraudulenta o abusiva, el empleado público pasaría a ser un trabajador fijo de plantilla sin necesidad de superar un nuevo proceso selectivo conforme a los principios de igualdad, mérito y capacidad. Es decir, nos retrotraeríamos a los inicios de la década de los años 90 del siglo pasado, donde imperaba la tesis jurisprudencial en la que se entendía plenamente aplicable el Derecho laboral, sobre la base de que una vez nacía la relación laboral entre la Administración y el empleado público, esta debía regirse por la normativa laboral que le fuera aplicable, puesto que lo contrario iría en contra del principio de legalidad — art. 9.1 CE— al que está sujeta la Administración. En suma, esta doctrina jurisprudencial entendía que la repercusión de los principios rectores de acceso al empleo público en la relación individual de trabajo se limitaba al estadio preliminar de la misma, referido al procedimiento de selección o reclutamiento del personal laboral por el organismo público ${ }^{15}$.

Pese a las dudas suscitadas, no considero que los cambios operados en este punto por el RDL 32/2021, ni el terminológico, ni la derogación de la disposición antedicha, han de interpretarse en el sentido expuesto. A mi juicio, existen argumentos de mayor contundencia para defender que tras la reforma laboral, el personal indefinido no fijo sigue siendo el efecto principal que se deriva de la contratación temporal irregular en las administraciones públicas. Las líneas maestras que, a mi modo de ver, avalarían esta interpretación, serían las siguientes:

10) Pervivencia de la necesidad de cohonestar las exigencias provenientes de dos ordenamientos jurídicos distintos. Las razones jurídicas que propiciaron la creación de esta figura jurisprudencial siguen plenamente vigentes. En efecto, ahora como antes, el problema de fondo surge por la imposibilidad de cohonestar las previsiones del derecho laboral para los casos en que un contrato temporal es irregular, esto es, la conversión de la relación laboral en fija; con las previsiones del derecho administrativo/constitucional, que impiden adquirir la condición de fijo al margen de un proceso selectivo acorde a los principios rectores del acceso al empleo público. Esta realidad, como señalaba, no se ha visto alterada lo más mínimo por la reforma laboral. Siendo así, entiendo que una interpre-

\footnotetext{
${ }^{14}$ BELTRAN DE HEREDIA RUÍZ, Ignasi, 2021, "Régimen normativo del Contrato Fijo-Discontinuo y de la Contratación Temporal (anterior y posterior al RDLey 32/2021)”, en: Una mirada crítica a las relaciones laborales [en línea]. Disponible en: https:// ignasibeltran.com/la-contratacion-temporal-laboral/\#321113 [Consulta en: 24-01-2022].

${ }^{15}$ Entre otras, SSTS de 11 de febrero de 1991; de 18 de marzo de 1991; de 6 de mayo de 1992 y de 22 de septiembre de 1993 (Rec. núm. 1414/1991).
} 
tación que supusiera avalar la transformación automática de una relación de servicios temporal en una permanente estaría conculcando las exigencias que por imperativo constitucional y legal han de presidir el acceso a la función pública. Podría razonarse que, en determinados casos, el trabajador que accedió a un puesto de naturaleza temporal ya superó un proceso de selección conforme a los principios rectores; sin embargo, esto no enerva la prohibición de transformación automática pues, aun en esos supuestos, nos encontraríamos ante una plaza o puesto de trabajo distinto que requeriría de un nuevo proceso selectivo. Más claro: la operatividad de los principios de igualdad, mérito y capacidad no se limita al momento de acceder al empleo público, sino que estos también despliegan sus efectos durante el desarrollo o promoción de la propia carrera profesional del empleado ${ }^{16}$.

20) Reconocimiento normativo de la figura a través del art. 8 EBEP. El EBEP, ni en su versión primigenia (Ley 7/2007) ni en la actual (RDL 5/2015) ha destinado una sola línea a la configuración del indefinido no fijo, ni al establecimiento de su régimen jurídico. La única referencia la encontramos en el art. 8.2 letra c) del Estatuto Básico, que, de manera decepcionante, se limita a reconocer su figura, al afirmar que, en atención a su duración, el contrato de trabajo podrá ser "fijo, por tiempo indefinido o temporal". Pues bien, esta previsión tampoco se ha modificado por la reforma laboral. Por tanto, sigue existiendo un reconocimiento normativo del personal indefinido no fijo.

Es lo cierto que el tratamiento dispensado por la Ley a un aspecto tan controvertido, la parquedad mostrada por el legislador, propició que la doctrina científica pusiera en cuestión que se efectuara tal reconocimiento, es decir, que la voluntad de la norma fuera la de contemplar esta figura; bien porque en realidad se trató de un error de redacción ${ }^{17}$; o bien porque si se atendía a la tramitación parlamentaria, no cabría alcanzar tal conclusión ${ }^{18}$. Sin embargo, sin desconocer la autoridad de los autores citados, discrepo de esta interpretación. Considero que ya en aquel momento se produjo tal reconocimiento, pues una cosa es que su intervención fuera vergonzante y otra que no fuera clara al diferenciar entre fijos, indefinidos y temporales (Personal laboral, ya sea fijo, por tiempo indefinido o temporal) ${ }^{19}$. Aquella distinción -inexistente hasta la fecha en el derecho positivo- sólo cobraba sentido si se insertaba en el debate jurídico que deriva del nacimiento de la figura del indefinido no fijo. ¿O es que, de no haber existido esta creación jurisprudencial, el legislador hubiera utilizado una redacción en la que distinguiera entre dos términos que extramuros del ámbito público siguen siendo sinónimos: indefinido y fijo? No parece que hubiera sido así. Es más, si acudimos a los precedentes normativos al Estatuto Básico, ni la Ley de Funcionarios Civiles del Estado (1964) ni la Ley de Medidas para la Reforma de la Función Pública (1984) llevaron a cabo esta distinción. Pero es que, además, la Comisión de expertos, que fue creada por Orden APU/3018/2004, de 16 de septiembre, y cuyo objeto, no se olvide, era el de "llevar a cabo los análisis y estudios previos, así como la elaboración de un documento que sirva de base para la posterior elaboración del anteproyecto de dicho Estatuto, en la propuesta que formuló como redacción, no establecía tal diferenciación, sino que proponía la siguiente: "Personal laboral, ya sea fijo o temporal". En suma, el hecho de que hubiera sido mucho más

${ }^{16}$ Así lo ha entendido, tanto la doctrina, entre otros, FERREIRA FERNÁNDEZ, A. Xavier, La provisión de puestos de trabajo en la Administración General del Estado, Madrid, Ed. Instituto Nacional de Administración Pública, 2002, págs. 56-58; PUERTA SEGUIDO, Francisco, «El acceso al empleo público», en AA.VV. (Dir. ORTEGA ÁLVAREZ, Luís), Estatuto Básico del Empleado Público, Madrid, Ed. El Consultor de los Ayuntamientos. LA LEY, 2007, págs. 404-405; como la jurisprudencia, entre otras, las SSTC 192/1991, de 14 de octubre; 212/1993, de 28 de junio y 80/1994, de 14 de marzo.

${ }^{17}$ SALA FRANCO, Tomás. y ALTÉS TÁRREGA, Juan Antonio., "La contratación de personal laboral en la Administración Pública”, Revista de Estudios Locales, núm. 112, 2008, pág. 69.

${ }^{18}$ BOLTAINA BOSCH, Xavier, "Trabajo. Amortización de puesto. Extinción de contratos. Indemnizaciones. Fin del debate jurídico: el procedimiento correcto de extinción de los contratos de los trabajadores indefinidos no fijos por amortización de puesto”, La Administración Práctica, num.11, 2014, BIB 20141368, p. 2

${ }^{19}$ SALA FRANCO, Tomás., "Acerca de los contratos indefinidos no fijos de plantilla en las Administraciones Públicas", en AAVV, Jurisprudencia social a debate, Valencia, Ed. Tirant lo Blanch 2015, pág. 186. 
sencillo repetir formulas anteriores que evitarían generar confusión; que la literalidad de la norma es clara; y, sobre todo, que ya entonces hacía más de una década que se estaba suscitando un intenso debate judicial y jurisprudencial en torno a esta figura, del que no era ajeno el legislador, lleva a pensar que los términos en que aparece redactado el precepto fue decisión consciente por parte del legislador.

30) Respaldo de la jurisprudencia comunitaria, interna y del legislador español a la tesis del indefinido no fijo. Otro argumento a favor de la continuidad del personal indefinido no fijo lo encontramos en su adecuación a la normativa europea, en concreto, a la Directiva 1999/70 CE del Consejo de Estado, de 28 de junio de 1999, relativa al Acuerdo Marco de la CES, la UNICE y el CEEP sobre el contrato de duración determinada, tal y como se desprende tanto de la jurisprudencia del Tribunal de Justicia de la Unión Europea (en adelante TJUE) como de la jurisprudencia de la Sala 4a del Tribunal Supremo. En el primer caso, debemos recordar que en la citada sentencia del TJUE, de 3 de junio de 2021 (Caso IMDRA) se afirmaba en su considerando número 73, que la asimilación de dicho personal con relaciones de servicio de duración determinada a los "trabajadores indefinidos no fijos" podría ser una medida apta para sancionar la utilización abusiva de los contratos de trabajo de duración determinada y eliminar las consecuencias de la infracción de lo dispuesto en el Acuerdo Marco. Un tanto de lo mismo ocurre con el Alto Tribunal espańol, que ha reiterado en innumerables ocasiones que la solución del indefinido no fijo se ajusta a nuestro derecho interno y a la citada norma comunitaria, en la interpretación que de la misma ha efectuado el Tribunal de Justicia de la UE.

La misma conclusión se extrae si fijamos nuestra atención en el derecho positivo. El legislador espańol sigue abogando por la presencia de esta figura, como demuestra la exposición de motivos de la citada Ley 20/2021. Norma que, no se olvide, ha sido aprobada unos días antes que la reforma laboral y en la que se aborda la cuestión nuclear por la que surge esta figura: temporalidad. Literalmente, se afirma que: "el TJUE comparte la postura, defendida por España, de que no cabe en nuestra Administración la transformación automática de una relación de servicio temporal en una relación de servicio permanente. Esta opción está excluida categóricamente en el Derecho español, ya que el acceso a la condición de funcionario de carrera o de personal laboral fijo sólo es posible a raíz de la superación de un proceso selectivo que garantice los principios constitucionales de igualdad, mérito y capacidad". A la vista de la rotundidad con la que se pronuncia el legislador, sería difícil y un tanto contradictorio interpretar que los cambios operados en el art. 15.4 y en la disposición adicional decimoquinta del ET por el RDL 32/2021 se dirigen a suprimir la figura del indefinido no fijo -las consecuencias que de ella se derivan, por ser más precisos-.

40) Existencia de referencias, previas a la reforma laboral de 2021, al término "fijo" y la razón de ser de la derogación de la Disposición adicional decimoquinta del ET. En otro orden, el cambio terminológico que se ha producido entre la versión del art. 15.3 ET y la del art. 15.4 ET, como principal argumento para defender una interpretación a favor de la desaparición del personal indefinido no fijo, pierde fuerza, en mi opinión, si tenemos en cuenta que ya antes de la reforma laboral, otros pasajes del ET utilizaban el término fijo sin que ello cerrase la puerta a la aplicación de la doctrina del indefinido no fijo. En efecto, el art. 15.5 ET ya señalaba para el supuesto de que se celebrasen sucesivos contratos temporales -en las condiciones que en dicho precepto se establecen- que la consecuencia inmediata era la adquisición de la "condición de trabajadores fijos". Pues bien, es un hecho notorio que, pese a los términos empleados, ello no ha sido óbice para que en el empleo público estos trabajadores no pasen a ser fijos de plantilla sino indefinidos no fijos.

Por otra parte, considero que la derogación de la Disposición adicional decimoquinta del ET (apartados 1 y 2) hay que interpretarla no tanto en relación con la desaparición del indefinido no fijo, como por la supresión del contrato de obra o servicio. En este sentido, recuérdese que el apartado pri- 
mero de esta disposición se refería: de un lado, a la Aplicación de los límites de duración del contrato por obra o servicio determinados y al encadenamiento de contratos en las Administraciones Públicas; y, de otro, aludía, implícitamente, a la figura del indefinido no fijo, pues señalaba que el empleado seguía en el puesto sin convertirse en fijo hasta que se cubriera definitivamente, momento en el cual se extinguía el contrato. La supresión del primer apartado hace que pierda sentido el segundo de ellos.

50) La entidad del cambio merece un pronunciamiento expreso y en la norma especifica. Por último, poniendo en valor que se trata de una de las cuestiones más complejas que planteaba $-y$ sigue haciéndolo- la irrupción de la Administración Pública en el ámbito de las relaciones laborales, generando múltiples conflictos en sede judicial; y que sus consecuencias prácticas, a la vista de los inadmisibles datos de temporalidad que se manejan en el sector público, sería de una magnitud enorme, su desaparición nunca debería ser fruto de una interpretación de la norma, por más que pudieran existir más o menos argumentos a favor o en contra, sino de un pronunciamiento expreso por parte del legislador. La entidad del cambio, insisto en ello, así lo exige, aunque sólo fuera en aras de establecer una mayor claridad en un panorama que, tradicionalmente, se ha caracterizado por la confusión y la inseguridad jurídica. A mayor abundamiento, creo que cualquier previsión en torno a esta figura, fuera su derogación o, quizás lo más razonable, su adecuada regulación normativa $^{20}$, debería efectuarse en la norma especial, pues no hay que olvidar que estamos ante una figura cuya virtualidad aplicativa sólo se produce en el ámbito de las administraciones públicas. Ello sin olvidar que en la tramitación de una eventual reforma de esta naturaleza se hace imprescindible la presencia de órganos como la Conferencia Sectorial de Administración Pública y la Comisión de Coordinación del Empleo Público; así como de organizaciones sindicales de máxima representación en el ámbito público como CSIF.

\section{El despido por causas empresariales en el sector público: ¿prohibición o aplicación del ré- gimen común?}

El último de los cambios introducidos por la reforma laboral con incidencia en el empleo público se contempla en su disposición derogatoria única. Se trata de la derogación de la Disposición adicional decimosexta del ET (DA.16a). Repárese, en todo caso, que su plena efectividad no se producirá hasta los tres meses desde la entrada en vigor del RDL 32/2021. Dicho esto, la mencionada disposición estatutaria, que fue introducida por la Ley 3/2012, se refiere a la aplicación del despido por causas económicas, técnicas, organizativas o de producción en el sector público.

La importancia del cambio introducido por la reforma laboral en este punto va a depender en gran medida de la interpretación que se haga del alcance de la derogación propuesta. Desafortunadamente, a diferencia de lo acontecido en otras materias, el legislador, a lo largo de la extensa exposición de motivos que se contiene en el RDL 32/2021, no nos ofrece ninguna pista sobre cuál era su propósito con esta medida. En una primera aproximación, cabrían dos posibles interpretaciones: a) entender que tras la derogación de la DA $16^{\mathrm{a}} \mathrm{ET}$, queda prohibido que una entidad del sector público pueda efectuar despidos por causas empresariales; b) considerar que la derogación se refiere al régimen especial, pero no impide el recurso a este cauce extintivo.

De las dos interpretaciones planteadas me inclino por la segunda de ellas. Las razones que me llevan a defender este planteamiento son las siguientes: 1) Con anterioridad a la reforma laboral de

\footnotetext{
${ }^{20}$ Un ejemplo concreto de propuesta de regulación puede verse en: LÓPEZ BALAGUER, Mercedes y RAMOS MORAGUES, Francisco. El personal «indefinido no fijo»: génesis, jurisprudencia y una propuesta de regulación legal, Valencia, Ed. Tirant lo Blanch, 2020.
} 
2012, ya era posible realizar despidos colectivos y objetivos por causas empresariales. En efecto, tanto la doctrina científica ${ }^{21}$ como los tribunales de justicia, avalaban esta posibilidad ${ }^{22}$. Es lo cierto que la forma de enjuiciar su viabilidad por parte de los órganos judiciales se hacía desde un prisma diferente al del sector privado, pues el foco de atención se ponía en el principio de eficiencia que ha de regir la actuación del ente público; 2) Sentado lo anterior, considero que la reforma laboral de 2012 ni establece, ni reconoce el despido por causas empresariales en el sector público, sino que se limita a proclamarlo, en el sentido que tiene este vocablo en la primera acepción del diccionario de la Real Academia de la Lengua Española, esto es, el de "publicar en alta voz algo para que se haga notorio a todos". Y a ello, añadió unas especialidades, en particular respecto a la operatividad de la causa económica que responden a la naturaleza pública del empleador; 3) el último argumento exige una breve referencia al art. 7 EBEP. Dicho precepto, como es sabido, se encarga de señalar el régimen jurídico aplicable al personal laboral. En términos generales, se indica que los empleados públicos laborales se rigen por la legislación laboral y por los preceptos del EBEP que así lo dispongan, bien porque tengan como destinatarios directos al personal laboral o bien porque se refieran de un modo genérico a los empleados públicos; categoría en la que hay que incluir a los contratados laborales. Pues bien, no hay ningún precepto en todo el articulado del EBEP que hable de la extinción del contrato por despido colectivo u objetivo basado en causas económicas, técnicas, organizativas o de producción. Siendo ello así, hemos de aplicar la remisión que el citado precepto legal efectúa en favor de la norma común, en nuestro caso, el ET.

En conclusión, sobre la base de los argumentos expuestos, considero que la nueva reforma laboral lo que hace es derogar la regla especial prevista en la DA 16a ET, pero deja expedita la vía de acudir a estos cauces extintivos en el sector público, siendo de aplicación lo dispuesto en el art. 51 y 52 c) ET.

En cualquier caso, si la interpretación dada por los tribunales de justicia fuera en favor de la primera de las tesis planteadas - prohibición de despedir por estas causas- hay un par de cuestiones que merece la pena traer a colación en este momento: de un lado, esa opción limitaría mucho las herramientas de que dispone un organismo público para afrontar coyunturas económicas difíciles, pues a la posibilidad de despedir que ahora se negaría, se suma la prohibición, ya existente, de aplicar la suspensión y reducción por causas empresariales en las Administraciones Públicas; de otro lado, merece la pena recordar que la todavía vigente DA $16^{\text {a }}$ del ET se refiere tanto a las Administraciones Públicas en sentido estricto, como a los entes sector público institucional, donde hay que incluir a las sociedades y/o fundaciones del sector público. Resulta llamativo que, a estas entidades, que muchas veces interactúan en el mercado como una empresa más, no se les permita esta vía extintiva.

\footnotetext{
${ }^{21}$ Es el caso, por citar un par de trabajos relevantes, GOERLICH PESET, José María. y NORES TORRES, Luís Enrique, "Reestructuración de plantillas en los entes locales: un nuevo supuesto de dudosa aplicación del Derecho del Trabajo en la Administración Pública", Justicia Laboral, núm. 4, 2000; y de MARTÍN VALVERDE, Antonio, "Especialidades de la extinción del contrato de trabajo del personal laboral al servicio de las Administraciones Públicas», Actualidad Laboral, núm. 14, 2004.

${ }^{22}$ En efecto, no son pocos son pocos los casos en que la jurisprudencia enjuicia este tipo de despidos cuando son acordados por entes públicos, sin poner en duda la posibilidad de su existencia. Entre otras, SSTS de 4 de julio de 1996 (Ro. 4006/1995); de 17 de julio de 1998 (Ro. 151/1998) y de 10 de marzo de 1999 (Ro. 2138/1998).
} 